
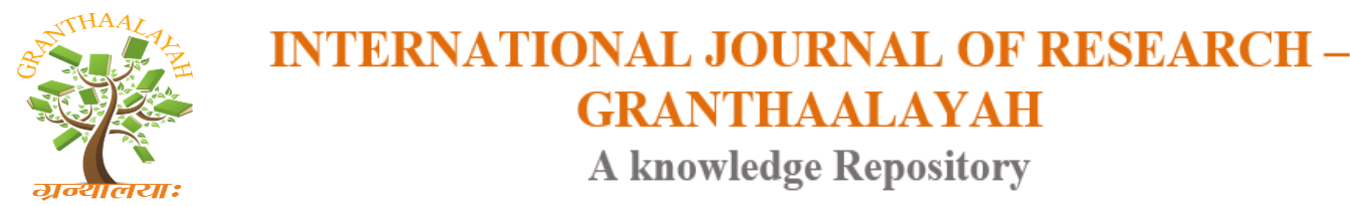

Science

\title{
STUDY AND DESIGN OF SINGLE PHASE CONVERTER USING OF SINGLE PHASE TRANSFORMER
}

\author{
Prof. G.R.Kumrey ${ }^{1}$, Dr. S. K. Mahobia ${ }^{2}$ \\ ${ }^{1}$ Assistant Professor, Department of Electrical Engg., Rewa Engineering College, Rewa (M.P.), \\ INDIA \\ ${ }^{2}$ Assistant Professor, Department of physics, Rewa Engineering College, Rewa (M.P.), INDIA \\ DOI: https://doi.org/10.29121/granthaalayah.v4.i8.2016.2562
}

\section{ABSTRACT}

The field of electrical transformer are most important equipment which is use to convert ac voltage or current like lower to higher, higher to lower without change in the frequency. its primary side and secondary side are isolate from each other and it can higher or lower voltage level the apparent value of electrical passive element like inductive, resistive. It use to transfer electrical energy for long distance with higher voltage level the electrical power transmission, distribution through transformer for factories and home. AC supply can easily generated by a convenient voltage and transformed into much higher voltage for transmission and distribution purpose.

Keywords:

primary winding turns, secondary winding turns, transformer core.

Cite This Article: Prof. G.R.Kumrey, and Dr. S. K. Mahobia, "STUDY AND DESIGN OF SINGLE PHASE CONVERTER USING OF SINGLE PHASE TRANSFORMER” International Journal of Research - Granthaalayah, Vol. 4, No. 8 (2016): 46-51.

\section{INTRODUCTION}

Single phase transformer

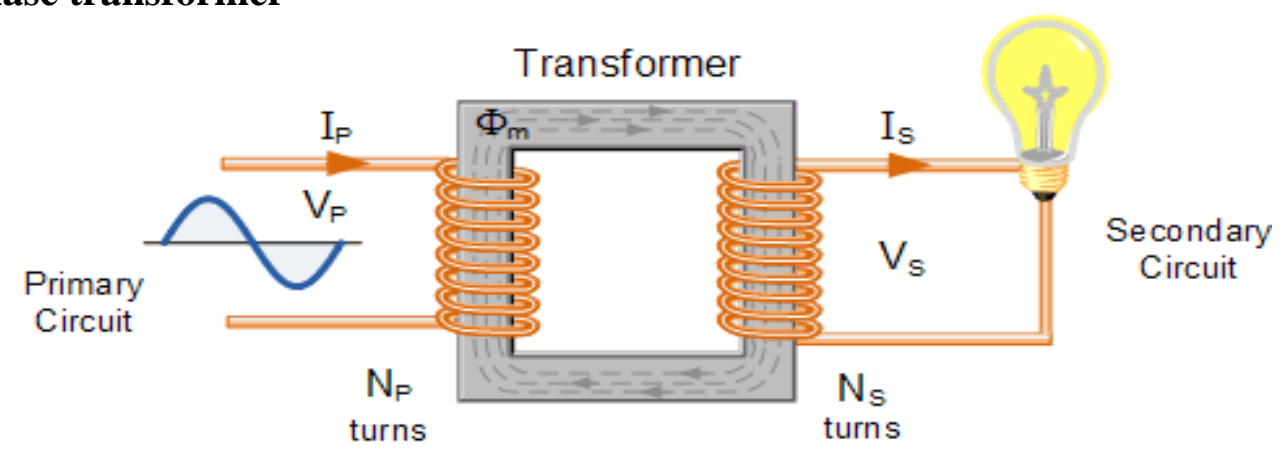

Figure 1: Single Phase Voltage Transformer 
Transformer consist of laminated core and the primary winding and secondary winding both are insulated by insulating material on the transformer core and each other. For low reluctance path transformer core is laminated. The winding which connected to supply is called as primary and which connected to load circuit is called as secondary winding, when primary is connected to higher voltage level then transformer is called step-down and when it connected lower voltage level is called step-up.

\section{Transformer construction (single phase transformer)}

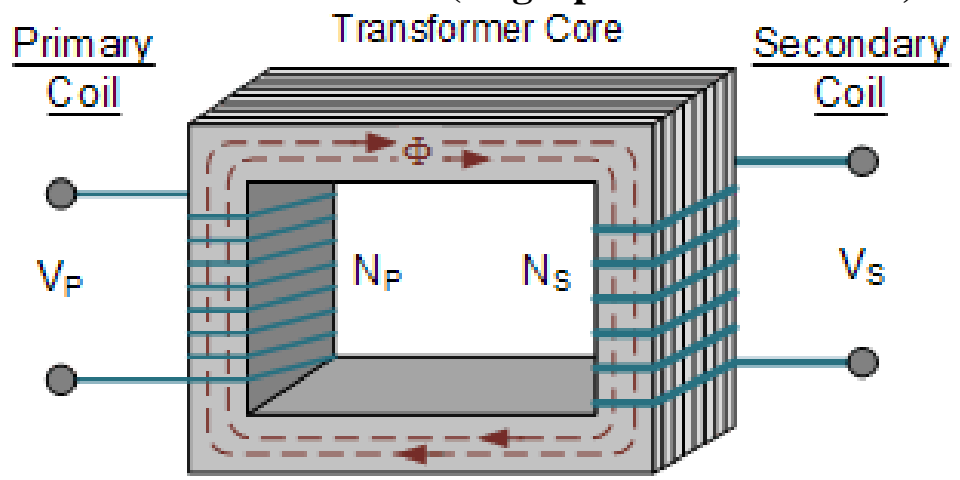

Transformer Construction

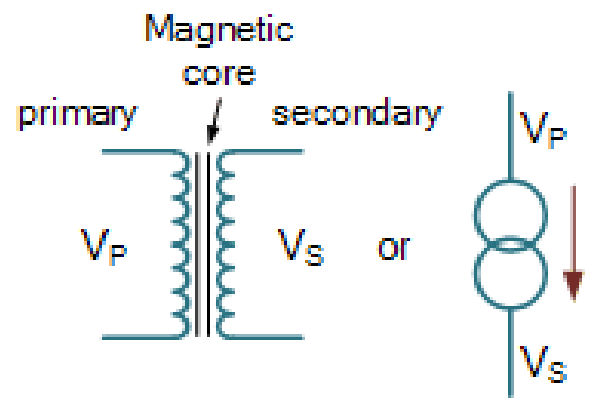

Transformer Symbols

Where

Figure 2: Transformer Construction (single-phase)

$\mathrm{V}_{\mathrm{P}}$ - voltage of primary winding side

Vs - voltage of secondary winding side

$\mathrm{N}_{\mathrm{P}^{-}}$primary winding side turns

$\mathrm{N}_{S^{-}}$secondary winding side turns

$\emptyset$ (phi) - is the magnetic Flux

A transformer operates to increase voltage level or decrease voltage level primary side to secondary side. In step up transformer voltage level increase in secondary winding side of transformer with respect to primary winding side, while in step down transformer secondary winding voltage level is decrease with respect to primary winding, when the voltage level of primary winding side and secondary winding side of a transformer is same that type transformer called impedance transformer and it is also called in ideal condition of transformer with respect current and voltage, this kinds of transformer is mostly use in adjoining the electrical circuits

In the transformer voltage difference is achieve by changing turns of transformer, turns ratio is divided by number of primary winding side turn to number of secondary winding side. The operation of transformer and voltage on secondary winding are depend on the turns ratio, no units of transformer turn ratio, it is comparison of transformer windings and they written with a colon such as 4:1 where 4 stands for primary side voltage in volts and 1 stands for secondary side voltage in volts, so we say that if turns ratio is change then voltage of winding is also change respectably with same ratio, it can say that for transformer voltage ratio $=$ turn ratio 


\section{THEORY OF IDEAL TRANSFORMER}

A transformer is said to ideal which has lossless core construction (like no ohmic resistance losses, no magnetic flux leakage, no core losses) only purely inductive coils are used for manufacturing of primary and secondary winding of ideal transformer.

We are consider an ideal transformer primary winding connected to ac voltage V1 and secondary winding open circuited, the voltage difference in primary and secondary side of transformer a current flow in primary winding, secondary winding is open so no current flow in secondary side of transformer then primary coil draw primary current Ip only and it magnetize transformer core, which has lags the primary voltage V1 by angle of $90^{\circ}$ degree and it is small in magnitude. This alternating magnetizing current case for production of alternating magnetic flux phi which is present in the core all time and proportional current when permeability of magnetic circuit constant. Magnetic flux in phase of current of primary winding. The magnetic flux is linked in both winding of transformer, this type of linking of flux is case to produces self-induce electromotive force in the primary winding, this induce EMF E1equal to V1and opposite it.

Similarly on secondary side of transformer an EMF E2 induced, this EMF is known as mutually inducted EMF by the process of mutual induction in secondary winding side. EMF induced in secondary is anti-phase of V1and magnitude of it is proportional to number of turns in secondary winding and rate of change in flux.

An ideal transformer we applied V1 alternating voltage in primary winding an alternating flux( $\varnothing$ ) is setup in transformer core and this flux is lined in both windings of transformer. The flux $(\emptyset \mathrm{m})$ linked in secondary is an mutual flux and it varied alternate and reach to its maximum value which is known as $\emptyset \max$ then

Average rate of change of flux $\frac{\mathrm{d} \emptyset}{\mathrm{dt}}=\frac{\emptyset \max }{1 / 4 \mathrm{f}}$

$$
\frac{\mathrm{d} \emptyset}{\mathrm{dt}}=4 \mathrm{f} \emptyset \max
$$

Average EMF induced in winding turns is equal to average rate of change in flux Average EMF induced per turns $=4 \mathrm{f} \emptyset \max$

Flux varies in sinusoidal form then induced EMF is also sinusoidal form but the sinusoidal wave form factor is 1.11 so the RMF value is 1.11 times of average value of induced EMF

Then RMF value of induced EMF per turns $=1.11 \times 4 \mathrm{f} \varnothing$ max if the number of turns in primary winding is N1 N2 then primary winding induced EMF in volts

$$
\mathrm{E} 1=4.44 \mathrm{fN} 1 \varnothing \max
$$

Similarly secondary side EMF in volts

$$
\mathrm{E} 2=4.44 \mathrm{fN} 2 \emptyset \max
$$

From above equations we deduce the flowing expression give the voltage ratio and turns ration of transformer

$$
\frac{\mathrm{E} 1}{\mathrm{E} 2}=\frac{\mathrm{N} 1}{\mathrm{~N} 2}=\mathrm{a}
$$

Where $\mathrm{a}=$ turns ratio of transformer 
In above equation we say that the voltage ratio of transformer windings is equal to the ratio of number of turns of transformer winding and primary winding induced EMF is in phase with secondary winding induced EMF of transformer because the induced by same flux

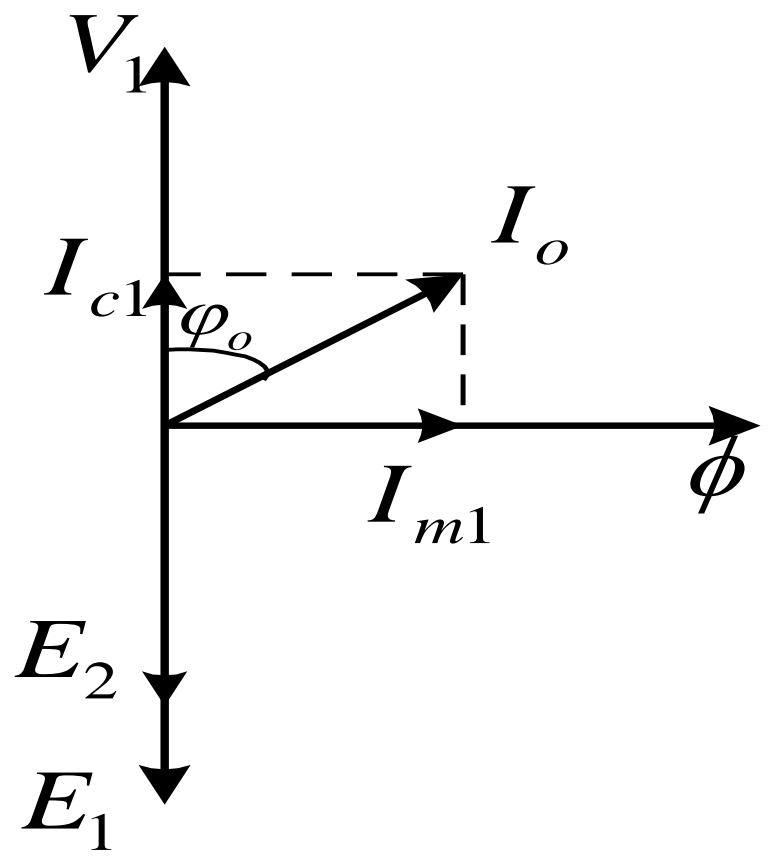

Figure 3: Transformer vector diagram

Vector E2 is shorter then E1 because secondary turns is fewer turns then primary winding .magnetizing current lags the applied voltage $\mathrm{V} 1$ by $90^{\circ}$ and in phase of magnetic flux $\emptyset$. This phase IO is no load current and Ic and Im are vertical and horizontal component of no load current. This vector diagram is on no load condition of transformer and Io, Ic and Im are infinitesimally small.

\section{EFFICIENCY}

The equipment is desired for operate at a high efficiency, in a transformer are no rotating parts show that no rotating losses. Which is well desired there efficiency may be high as $99 \%$.

$$
\begin{aligned}
\text { Efficiency } \eta & =\frac{\text { output }}{\text { input }} \\
& =\frac{\text { output }}{\text { output+losses }} \\
& =1-\frac{\text { iron losses+copper losses }}{\text { output+iron losses+copper losses }}
\end{aligned}
$$

\section{CENTER TAPPED TRANSFORMER}

When we are needed two phase 3 wire supply system then we are tapped the secondary winding of transformer in center point so it is known as center tapped transformer, in this type of tapping secondary winding turns are divided in two equal parts and this is provide two separated secondary winding voltage $\mathrm{V}_{\mathrm{A}}$ and $\mathrm{V}_{\mathrm{B}}$ with a dot connection and secondary winding voltage is 
proportional to supply voltage $\mathrm{V}_{\mathrm{P}}$ so that power of each winding is same and the determination of voltage in each winding by turns ratio

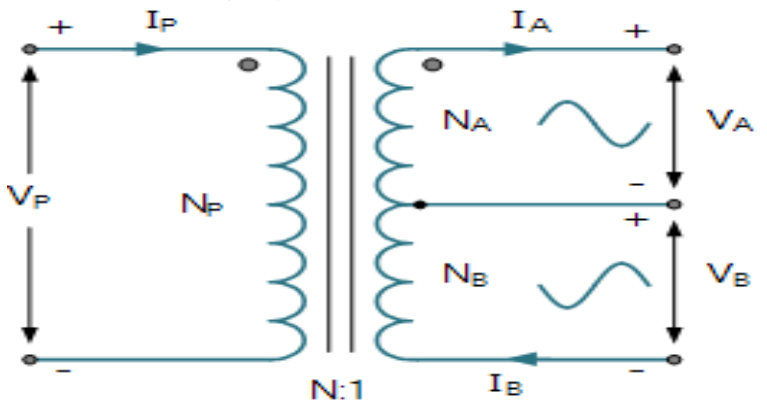

$$
\begin{aligned}
& V_{\mathrm{A}}=\frac{\mathbb{N}_{\mathrm{A}}}{\mathbb{N}_{\mathrm{P}}} \cdot \mathrm{V}_{\mathrm{P}} \\
& \mathrm{V}_{\mathrm{B}}=\frac{\mathbb{N}_{\mathrm{B}}}{\mathbb{N}_{\mathrm{P}}} \cdot \mathrm{V}_{\mathrm{P}}
\end{aligned}
$$

Figure 4: Transformer on center tapped diagram

A center tapped transformer and tapping point is on the middle for providing to equal in magnitude and opposite in direction, that they $180^{\circ}$ electrical degrees out of phase. However in center tapped transformer has on disadvantage using of ungrounded center tapped, is produced unbalance voltage in the two secondary winding because unsymmetrical current flowing the dot connection and unbalance load.

\section{Center tapped using a dual voltage transformer}

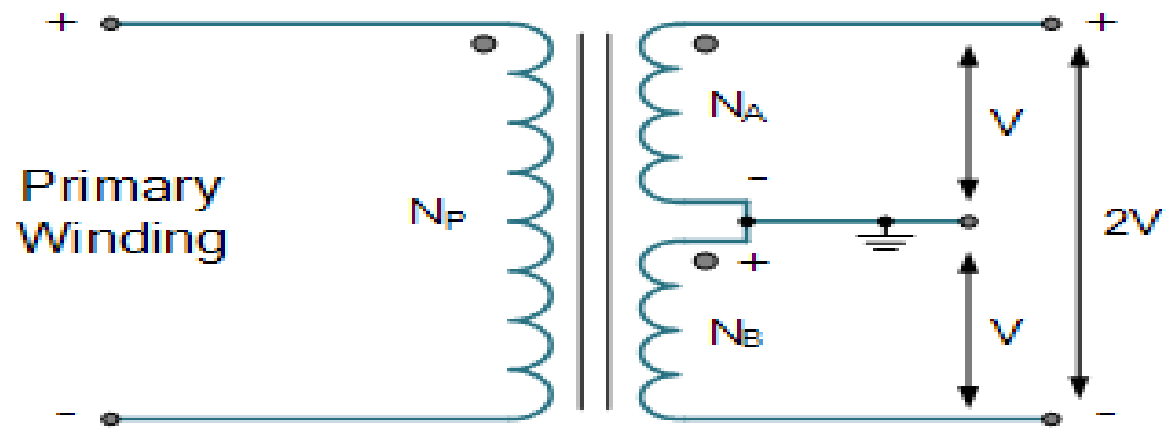

Figure 5: Center-tap Transformer using a Dual Voltage Transformer

We connecting the secondary winding in series we can use the center link as the tap, if the voltage of each secondary voltage $\mathrm{V}$ then the output of secondary winding is equal to $2 \mathrm{~V}$. The transformer which has multiple winding may uses in electrical and electronics circuit they use for different load by supply of different secondary voltage. This type of connection give higher voltage or currents.

\section{ELECTRICAL POWER IN A TRANSFORMER}

There is some basic parameter for transformer power rating is one of them, power rating of a transformer is multiplied of voltage and current. We obtain power rating in volt amperes unit in small single phase transformer but the transformer use in transmission and distribution of electrical power is in mega volt ampere,(MVA ) and kilo volt ampere (KVA).

In ideal transformer ignoring losses power in secondary winding side will be the same as the primary winding side, they are constant voltage equipment. Thus power ratio of ideal transformer is equal to one (unity) voltage V multiplies current I will remains constant. 


\section{REFERENCES}

[1] Paul B. Zbar and Albert P. Malvino, Basic Electronics: A Text - Lab Manual, 5th edition, Tata McGraw-Hill Publisher, 2005.

[2] O.P Arora, Power Electronics Laboratory: Experiments \& Organization, 1st edition, Wheeler Publishing, 1993.

[3] Electrical Science” by J. B. Gupta

[4] A Text book of Electrical Technology" by B. L. Thereja Vol-11

[5] Electrical Engineering Fundamentals" by Del Toro

[6] Electric Circuits" by James Nelson (Pearson publication)

[7] Basic Electrical Engg." By DC Kulshreshtha, TMHill. 